\title{
CONSTRUÇÃO DAS DIFICULDADES DE APRENDIZAGEM EM CRIANÇAS ADOTADAS
}

\author{
SUELI CRISTINA DE PAULI \\ Professora e coordenadora dos Cursos de Pós-Graduação (lato sensu) em \\ Psicopedagogia, Educação Infantil, Educação Especial e Psicomotricidade, do Departamento \\ de Ciências Humanas do Centro Universitário Barão de Mauá - Ribeirão Preto-SP \\ scpauli@ig.com.br
}

\section{MARIA CLOTILDE ROSSETTI-FERREIRA}

Professora titular do Departamento de Psicologia, da Faculdade de Filosofia Ciências e Letras da Universidade de São Paulo - Ribeirão Preto-SP

mcrferre@usp.br

\section{RESUMO}

Breve revisão bibliográfica acerca da usual concepção de que crianças adotivas comumente possuem dificuldades de aprendizagem escolar. Investigações sobre o processo de construção de dificuldades de aprendizagem em crianças adotivas são praticamente inexistentes na produção científica brasileira e internacional. Algumas poucas pesquisas fazem referência direta aos problemas de aprendizagem desses sujeitos, relacionando o sintoma com o curto ou longo tempo de institucionalização por eles vivenciado. Já a literatura psicopedagógica aponta alguns sintomas apresentados por essas crianças, os quais teriam influência sobre a sua não aprendizagem, tais como: dificuldades na estruturação egóica, baixa autoestima, rebaixamento intelectual associado a problemas de comportamento, hiperatividade, desatenção. Todavia, esses problemas não são descritos em quantidade e/ou profundidade, de sorte que sobre a questão há uma escassez, um vácuo, o que indica a necessidade de realização de estudos específicos que tornem visíveis tanto o número de ocorrências das dificuldades de aprendizagem entre adotados quanto os aspectos que contribuem para a constituição (ou não) de tais sintomas.

CRIANÇA ADOTADA - DIFICULLDADES DE APRENDIZAGEM - COMPORTAMENTO PSICOLOGIA DA CRIANÇA

\section{ABSTRACT}

CONSTRUCTION OF LEARNING DIFFICULTIES BY ADOPTED CHILDREN. The objective of this work is to present the results of a brief bibliographic review concerning the common idea that adopted children often experience difficulties in school learning. Studies of how difficulties

Este texto resulta do projeto de pesquisa de pós-doutorado Dificuldades de Aprendizagem em Crianças Adotivas (Pauli, 2002). 
in learning arise in adopted children are quite scarce both in Brazil and internationally. Some of the few researches found make direct reference to the problems in learning for these children usually relating these difficulties to the length of time children are in institutions. The literature in educational psychology has previously identified some symptoms associated with adoption - for example, problems in ego strength, low self-esteem, reduced intellectual functioning associated with behavioral problems, hyperactivity, and deficits in attention. However, these problems are not described with either depth or reliability. This suggests that there is a shortage, a vacuum of knowledge, requiring the execution of specific studies, which might make visible the actual magnitude of learning difficulties among adopted children and as well illuminate the factors that contribute (or that do not contribute) to these symptoms.

ADOPTIVE CHILD - LEARNING DISABILITIES - BEHAVIOUR - CHILD PSYCHOLOGY

Não digas: este que me deu corpo é meu Pai.

Esta que me deu corpo é minha Mãe.

Muito mais teu Pai e tua Mãe são os que te fizeram

Em espírito.

(Cecília Meireles, Cânticos, XXIV)

O recorte apresentado a seguir foi produzido por uma criança de nove anos, em resposta à terceira história (fábula do cordeirinho) do Teste das fábulas... (Cunha, Nunes, 1993), teste projetivo utilizado em minha tese de doutorado (Pauli, 2002).

O cordeirinho fala assim: "Ah não! Mamãe, eu quero leite!" E a mãe fala assim: "Ora bolas, menino, você é teimoso, não tenho leite!" Ele disse: "Mas eu quero, mas eu quero!" Falô assim: Sinão eu vô dá um para cada um e vô tê adoa [doar] um, pra alguém.. aí deixá na porta de cada um. Porque um qué leite o outro qué leite, eu não tenho leite bastante! Então, aí né, aí a mãe falo assim: "ah, eu vô dá você pra aquela vizinha! (Poliane)

Menina muito pobre e com muitos irmãos, Poliane narra algo de sua vivência que assombra a ela e a muitas crianças, cujos pais se veem sem condições de garantir-lhes as necessidades fundamentais e cuidar delas: "doá-las" a outras pessoas, supostamente com mais recursos materiais, "com bastante leite". No Brasil, a "solução" da "mamãe cordeirinho" - dar a criança a alguém ou mesmo colocá-la em um abrigo para menores - não é incomum. Mariano (2003), em 
estudo documental na cidade de Ribeirão Preto, apontou que a falta de condições financeiras para o cuidado de suas crianças é um dos principais condicionantes que leva os pais biológicos a solicitar a colocação de seus filhos em instituições/ abrigos e/ou em famílias substitutas, mediante processos de guarda, tutela e/ou adoção. Trata-se de assuntos que, usualmente, caminham e são abordados de forma interligada, e com frequência, por meio de uma rígida relação de causa e efeito. Têm e refletem os sinais da pobreza, do desinteresse e da exclusão, sofrida por significativa parcela da população brasileira. Habitualmente, esses acabam sendo os únicos recursos que restam às famílias, fato que ocorre por que, no país, há apenas tentativas de diversas ordens, dispersas e embrionárias, tanto no que tange a políticas públicas quanto às condições estruturais de assistência, que auxiliem os familiares no cuidado dos filhos e previnam que estes tenham que ser deles afastados. Neste sentido, as "soluções" de adoção são caracteristicamente ambíguas, uma vez que constituem medidas de "acolhimento e proteção" compreendidas também como "problemas": são marcadas por mitos e fantasias negativas e também pela complexa realidade do funcionamento dessas alternativas na prática, que ainda deixa a desejar, apesar das exigências do Estatuto da Criança e do Adolescente - ECA (Brasil, 1991).

No que tange à adoção de crianças, trata-se de uma prática social bastante usada. No cenário brasileiro, sua consolidação se dá de diferentes maneiras, em diferentes classes sociais, e historicamente representa, antes de tudo, uma importante forma de circulação e socialização de crianças (Fonseca, 2002). Juridicamente, é o ECA que regulamenta essa prática, a qual deveria representar uma vantagem para a criança por garantir seu bem-estar biopsicossocial. Sendo considerada uma saída viável para solucionar o problema de crianças que vivem em situação de risco psicossocial, encontra-se amparada em forte convicção de que o contexto familiar representa o melhor lugar para o desenvolvimento infantil, para o equilíbrio emocional da criança, especialmente porque as instituições de abrigo para essa clientela têm sido caracterizadas como de má qualidade, lugares de exclusão e não de acolhimento e educação (Oliveira, 200 I). Não se trata, no entanto, de uma questão sem controvérsias, apesar de muito disseminada. Por exemplo, no meio científico em que se pesquisa sobre o tema, a família é vista sob aspectos contraditórios; como a principal fonte externa de recursos para um desenvolvimento sadio e mecanismo protetor para lidar com a adversidade, ou como um mecanismo de vulnerabilidade, de risco. 
A abordagem da "adoção" em seu aspecto psicológico, que apaga usualmente as diferentes perspectivas em que esse assunto pode ser compreendido, encontra-se fortemente alicerçada por uma visão negativa da família. Decorre daí um amplo conjunto de pesquisas demarcadas pela patologização de crianças e famílias, ideologia dominante, a qual tende a interpretar as situações vividas por esses sujeitos, como, por exemplo, a ruptura da relação com os pais, a probabilidade de permanência em abrigos e a privação de uma relação estável com uma pessoa específica, como fatores de risco, prejudiciais ao desenvolvimento. Nessa direção, a maioria dos estudos deixa claro que um passado com privações e maltratos não é gratuito para o desenvolvimento, equivale a uma sina: fatalmente se concretizará em um destino de desequilíbrios e anormalidades, um histórico de comprometimentos generalizados, dentre os quais estão aqueles relacionados ao fracasso na aprendizagem escolar.

Se em adoção, as experiências de privação e negligência familiares são definidas como fatores de risco ao desenvolvimento, também o fracasso escolar tem sido considerado como uma ocorrência social debilitadora, com possibilidade de levar ao sofrimento e reduzir a capacidade do indivíduo de enfrentar as adversidades posteriores. Na questão do insucesso escolar o binômio família-escola tem sido apontado como importante aspecto influenciador. Em vista disso, Rutter ( 1 989) afirma que discórdia e descontinuidade nas relações têm efeito maior sobre o funcionamento socioemocional e comportamental, enquanto oportunidades para a aprendizagem ativa parecem ter maior impacto sobre o desenvolvimento cognitivo, mesmo que a superposição desses acontecimentos e seus efeitos não possa ser completamente negada. Nesse sentido, a escola tem sido concebida tanto como "recurso de proteção" (se instrumentaliza cognitivamente a criança e auxilia no aumento de estratégias adaptativas, promovendo maior autoestima, autoeficácia e mais oportunidades), quanto como "fator de vulnerabilidade" (se acontecer o fracasso, sobretudo em um período sensível, como no momento de ingresso na escolarização formal e/ou na adolescência).

Cabe esclarecer ainda que a maioria dessas pesquisas fundamenta-se em um conceito de desenvolvimento que define, a priori, quais fatores protegem indivíduos do sofrimento e quais fatores induzem sofrimento e descompensações de toda ordem. Para o caso de proteção, abordam a noção de resiliência, que é a habilidade de resistir ao stress a qual se apresenta em crianças que 
crescem em condições desfavoráveis, e que as induz a se comportarem como adultos com alto grau de bem-estar (Rutter, 1987)'. Um outro alicerce teórico desse tipo de pesquisa é o conceito de "período sensível", segundo o qual o desenvolvimento da pessoa não está determinado por um encadeamento de fases rígidas, mas em seu caminho há momentos em que determinadas influências têm maior peso.

Dentro de um contexto social em que o desenvolvimento acadêmico é considerado prioridade e que favorece a saúde mental da criança, os eventos familiares vivenciados por adotivos são vistos como determinantes de seu insucesso, já que sua história pretérita traz, muitas vezes, um conjunto de acontecimentos que, segundo a ciência psicopedagógica, justificam essa problemática. É exatamente essa concepção, com frequência aceita também pelo senso comum, que se pretende discutir neste trabalho, sendo que a discordância dessa visão fatalista é o principal mote da argumentação. Isso porque se acredita que, como na maioria das outras patologias "encontradas" em sujeitos adotivos, também a "dificuldade de aprendizagem" já é apregoada a priori, calçando um caminho para que a dificuldade realmente se concretize. Essa concretização encontra-se, no caso, alicerçada em um conjunto de ideias e na própria maneira de realizar pesquisas, tanto sobre sujeitos adotivos como com sujeitos com dificuldades para aprender.

\section{"CRÔNICA DE UMA PSICOPATOLOGIA ANUNCIADA": O LUGAR IDEOLÓGICO DO INDIVÍDUO ADOTADO}

Em torno de temas como "desenvolvimento de crianças adotadas" e "crianças que fracassam na escola" circulam certas concepções, produtos histórica, social e ideologicamente construídos, que anunciam e prognosticam trajetórias

I. Nesse aspecto, Luthar e Zigler ( 199 I) reúnem três pontos que atuam como "fatores protetivos", aumentando a resiliência perante a adversidade: a. características de personalidade como autonomia, autoestima e orientação social positiva; b. harmonia e afeto familiar, com ausência de desavenças; c. disponibilidade de um sistema de suporte externo que encoraja e reforça os esforços enfrentamento. Obviamente, tais fatores são geralmente descritos como "inadequados" entre indivíduos adotados ou institucionalizados, o que "justifica" a ampla problemática que, supostamente, neles se instala. Da mesma forma, diversas pesquisas sobre o fracasso escolar fundamentam-se e/ou investigam esses aspectos, atribuindo o problema na aprendizagem às desordens várias nesses fatores. 
quase sempre marcadas por rígidas atribuições de sentidos. Questões relativas, por exemplo, à influência e ao peso de fatores biológicos da família de origem e do contexto de vivência, aliados aos diversos aspectos oriundos do funcionamento e da dinâmica da instituição familiar, entre estes, os mitos acerca da maternidade/ paternidade e filiação, as características das organizações - a escola, no caso de fracasso escolar, e instituições de abrigamento, no que se refere à adoção - bem como as políticas públicas que regulamentam esses assuntos, constituem partes do cenário essencial que enreda, direciona certos sentidos e interdita outros em ambas as temáticas. Há, portanto, um amplo movimento ideológico que arrasta esses temas para lugares marcados por pré-concepções que se assemelham em alguns aspectos, visto que revelam um debate científico que é histórico para a psicologia do desenvolvimento: o orgânico versus o contextual.

No que tange especificamente às crianças adotivas, um conjunto de ideias é recorrente em nossa sociedade e exemplifica com maestria o duelo entre essas tendências teórico-ideológicas. Nesse ideário, a visão organicista - que se caracteriza pelo determinismo, previsibilidade e continuidade no desenvolvimento, menosprezando o importante papel desempenhado pelos aspectos que envolvem o ambiente atual em que a criança vive, a rede de relações e recursos da própria criança - mostra-se dominante, reafirmando uma sina marcada pelo mecanicismo e fatalismo, a qual tem perpassado discursos e atuações sobre a prática social da adoção, também se afigurando, a partir daí, uma série de receios e fantasias por prováveis adotantes e educadores da criança.

Balone (2003) enumera e exalta algumas crendices que permeiam essa temática, que, segundo ele, não são preconceitos, porque legitimados pelo conhecimento científico, muito embora não cite referência alguma. Há, por exemplo, o temor de adoções inter-raciais, pois o preconceito seria intrínseco à espécie humana. Existe, ainda, o receio de adotar crianças com saúde frágil, por motivo das pendências que os adotantes teriam quanto aos cuidados especializados. Os possíveis adotantes também se amedrontam ante a possibilidade de que os pais biológicos possam vir a solicitar a volta da criança, dúvida que, segundo o autor, possui nexo, visto que a mídia divulga que isto realmente pode vir a acontecer. A esse respeito, Costa (1984) explica o medo, referindo-se à "fantasia de roubo", em que inconscientemente os adotantes sentem-se como se tivessem "roubado" a criança dos pais biológicos. Temem, então, que a criança, ao saber ser adotada, se torne rebelde e procure ser 
requisitada de volta pelos progenitores. Há igualmente o medo de adotar crianças cuja origem dos genitores seja desconhecida, porquanto existiriam fantasias de influências de elementos hereditários na formação da personalidade (Santos, 1991). Mitos como esses culminam em outro temor muito comum: o de adotar crianças mais velhas ou que tenham passado extensos períodos em abrigos, pois estas seriam marcadas pela sua história. Decorre, em parte, daí a constituição e manutenção da crença de que a criança adotada, especialmente aquela tardiamente adotada, fatalmente desenvolverá perturbações emocionais e/ou comportamentais, transtornos estes que Balone (2003) diz serem "estatisticamente confirmados". No entanto, no ponto de vista da pesquisa, isso precisa ser mais bem esclarecido.

\section{O ACIRRADO DEBATE CIENTÍFICO SOBRE O DESENVOLVIMENTO "ANORMAL" DE CRIANÇAS ADOTIVAS}

A supremacia dos laços consanguíneos para o cuidado de crianças é uma ideologia dominante em nossa sociedade. Em parte, é desta ideia que emana a concepção hegemônica encontrada em diversas tendências teóricas, da pré-destinação à psicopatologia das crianças separadas da família biológica. Seu histórico de vida, marcado por estressores psicossociais de diversas ordens, aos quais se somam vivências institucionais, é visto a partir de uma conotação negativa, ideia predominante que retumba em diferentes âmbitos da vida social, permeando tanto os discursos de senso comum como os do meio científico sobre a adoção. $\bigcirc$ estigma do abandono e da carência funciona, então, como uma tatuagem nessas crianças, especialmente quando são institucionalizadas por algum tempo (Guirado, 1986) e/ou adotadas tardiamente, fatos vistos como "fatores de vulnerabilidade" que comprometem seu processo adaptativo. Como se esses eventos tivessem o mesmo sentido para todos que o vivenciam, e fosse impossível a essas crianças estabelecer novos vínculos de apego, interagir significativamente com outros que não os progenitores que, por alguma razão, não podem cuidar delas, este acontecimento é encarado como um marco traumático, que desemboca naquilo que tem sido descrito como "peculiar desenvolvimento psicológico do adotado" (Zavaschi, Araújo, 1988, p.613).

âmbito da produção do conhecimento científico sobre a adoção, quase sempre, reflete esses tabus e, muitas vezes, os reforça. Os resultados de muitas 
pesquisas sobre o tema acabam referendando ideias que circulam no imaginário social sobre e para a adoção, estimulando o preconceito que ainda marca essa prática. Muitas pesquisas mostram resultados construídos com o objetivo de investigar as irregularidades no desenvolvimento de crianças com histórico de privação materna e de institucionalização, priorizando delineamentos de coleta de dados longitudinais com medidas comportamentais e pareamento de grupos de adotados e não adotados e/ou, de adotados em diferentes idades, ou, simplesmente, baseando suas interpretações em perspectivas teóricas norteadas pela primazia de relações de causa e efeito, como, por exemplo, a teoria psicanalítica. Nesses estudos, a criança é focalizada como detentora de anomalias - um verdadeiro "compêndio de psiquiatria" - relegando às atuais condições ambientais e circunstâncias de vida um papel inócuo ou irrelevante. Além disso, concentram as análises nos comportamentos que se mantêm nos processos de continuidade das ações humanas, tomando essa versão como a verdade, quando se trata apenas de uma parte de um todo interacional muito maior.

Os transtornos apontados no desenvolvimento já foram mostrados em estudos muito antigos, como os realizados por Spitz (1945). Estudos mais atuais corroboram esses prognósticos ruins e continuam apontando a formação e o rompimento dos vínculos afetivos como um acontecimento responsável por muitas consequências maléficas, algumas de caráter inalterável, quanto ao desenvolvimento emocional e social de crianças e adolescentes privados do convívio com a família biológica, com vivência em instituições e/ou adotadas. Há ainda estudos, como os citados por Weber (2003) e Pereira e Santos (1999), que destacam a privação materna como causador de importantes atrasos no desenvolvimento biopsicossocial de crianças adotivas, e o trabalho de Wieder (1977), que aponta a vulnerabilidade das pessoas adotivas a problemas emocionais, citando pesquisas que revelam a incidência de 15\% a 30\% de indivíduos adotados na população com sintomas psiquiátricos, o que excede os $2 \%$ indicados pelo censo geral. Sentimento de abandono, baixa autoestima, a identidade e os processos de identificação, o desenvolvimento do ego, as alterações na elaboração do complexo de Édipo e, por conseguinte, na formação do superego, comportamentos impulsivos e antissociais, hipercinesia, condutas rebeldes ou destrutivas, "dificuldades na aprendizagem" e problemas de relacionamento são, segundo Brinich (1980) e Garma et al. (1985), aspectos 
marcadamente afetados no paciente adotivo, queixas que justificam a frequente procura de auxílio psicológico para essas crianças, principalmente no período de latência. Na adolescência, são apontados ainda as frequentes fugas de casa, os pequenos roubos ou, então, a intensificação da agressão que chega a níveis insuportáveis. Também são usuais comportamentos de amor aos esportes e atividades de alto risco.

A privação materna e a institucionalização têm sido consideradas, por ampla literatura científica, o cerne e a gênese de todos os problemas que se desencadeiam posteriormente no desenvolvimento de crianças com essas experiências. Corroborando essa visão, vários estudos realizados com crianças que viveram em orfanatos estatais da Romênia, onde a qualidade do atendimento era precária, observaram relações entre ocorrências de apego inseguro, apego atípico e privação institucional, com o estabelecimento de sintomas como rebaixamento intelectual, problemas de comportamento, comportamento "pré-autístico", desatenção, hiperatividade, comportamentos estereotipados em proporção direta com a idade da adoção: quanto mais velhas, maior a incidência de problemas (Chisholm, 1998). Já as pesquisas de Rutter, Kreppner e O'Connor (200 I) e de Rutter e Thomas (2004) mostram que os problemas constatados obtêm intensa melhora após a inserção da criança na família adotiva, sendo que tanto a quantidade e intensidade dos problemas observados quanto sua recuperação depende da idade da adoção e das condições iniciais da criança. Tais resultados indicam que as sequelas podem ser "praticamente" superadas se o novo ambiente for de qualidade.

\section{SOBRE A APRENDIZAGEM ESCOLAR DA CRIANÇA ADOTIVA: INIBIÇÃO DA CURIOSIDADE}

Algumas pesquisas mencionadas sobre crianças adotivas fizeram referência direta aos problemas de aprendizagem escolar das crianças com curto ou longo tempo de institucionalização. Além dessas referências, diversos trabalhos apontaram sintomas apresentados por essas crianças que a literatura científica psicopedagógica relata ter influência sobre a não aprendizagem. São alguns exemplos: a dificuldade na estruturação egóica, a baixa autoestima, o rebaixamento intelectual associado a problemas de comportamento, a hiperatividade, a desatenção. Entretanto, no que tange à aprendizagem, esses problemas não 
são descritos em quantidade e em profundidade, indicando a necessidade de realização de mais estudos específicos. Há ainda uma série de trabalhos de perspectiva psicanalítica que defendem que a curiosidade é um outro importante aspecto afetado pelas experiências da criança adotada que interfere intimamente na capacidade para a aprendizagem. Pesquisadores afirmam que a curiosidade das crianças pode ser inibida diante da dificuldade que os adotantes venham a demonstrar para revelar a verdade sobre sua origem, por conta da dor que isso possa representar para todas as partes envolvidas. Woiler (1987, p.56) atribui às dificuldades notadas neste campo a uma precária constituição egóica "que carece de espaço psíquico para os processos de pensamento e no qual devem tramitar intensas angústias e fantasias que se traduzem mediante ação motora". A autora ressalta que é nesse sentido que os mecanismos de defesa, como os de negação, cisão, isolamento e repressão, favorecem um distanciamento das circunstâncias de aprendizagem na criança adotada, argumentos que vão ao encontro dos de Fernandez, importante psicopedagoga argentina:

...um casal pode ser infértil e [...] talvez não se conforme com sua infertilidade, transformando em segredo a origem do filho adotado. Enterrar-se-á então, junto com o conhecimento sobre a origem da criança, a atitude investigadora, [...] obstruem-Ihe a possibilidade de simbolizar [...]. (1990, p. I23)

Desse modo, ao aprender, a criança, a todo o instante, é impelida a conhecer as conjunturas dolorosas de infertilidade, repúdio e adoção que tanto ela deseja negar, isolar, cindir e reprimir. Tais percepções também se ancoram em Levinzon (1 999), Piccini (1986), Costa (1 984), cujas observações clínicas explanam que, consciente ou inconscientemente, a criança sabe a verdade, que quando não revelada pode desencadear uma série de distúrbios, como o desinteresse pelos estudos e o uso de drogas. Pereira e Santos ( 1999, p.236) esclarecem ainda: "O interdito, em vez de ter um papel estruturante, aprisiona o psiquismo no campo da impossibilidade, já que lhe é vedado nomear determinados conteúdos ansiogênicos".

Não obstante, a fundamentação determinista desses estudos na interpretação da continuidade e agravamento dos comportamentos observados entre adotivos não dá conta de explicar a diversidade e as contradições encontradas no desenvolvimento de crianças adotivas. Como consequência dessas con- 
cepções, verifica-se um processo de apagamento da ideia de que o percurso de desenvolvimento de um indivíduo não é único e sim dinâmico, sujeito a mudanças, a constantes adaptações e rearranjos (Rossetti-Ferreira, Amorim, Silva, 2004). A diversidade e as descontinuidades, postas em segundo plano na maioria das pesquisas apresentadas até aqui, baseiam-se e reforçam a noção do caráter estável da pessoa, crença que Rutter (1989) e Schaffer (2000) afirmam ter sido prevalente até algumas décadas atrás, escorada, sobretudo, em referenciais teóricos que postulam a intensa influência das primeiras relações afetivas no desenvolvimento ulterior.

Tentando alargar essa visão dominante, há pesquisas um pouco mais otimistas (Badinter, 1985) que indicam efeitos maleáveis porque tentam relativizar a ideologia da consanguinidade e os efeitos negativos que teria o cuidado de crianças realizado por outros que não os pais biológicos, desfazendo a ideia de que o cuidado de pai e mãe é algo biologicamente natural e mostrando a ligação pais e filhos como sendo construída social, histórica e ideologicamente. Badinter baseia seu livro sobre o mito do amor materno em uma visão contextualista, que considera os fatores atuais, a relação de interdependência de variáveis diversas, o homem como sujeito de sua história, defendendo a ideia de que, "apesar do passado", a criança adotiva tem um longo caminho pela frente.

Nessa direção encontramos, por exemplo, os trabalhos de Weber (2003), Dolto (1989), Fogel (1993), Fonseca (2002) e Lewis (1999) que deslocam o foco de atenção da criança, atitude própria de uma visão mais biologizante, para o contexto, abandonando uma visão de causalidade e propondo um "giro" na compreensão de desenvolvimento humano hegemônica na ciência. Dessa forma, a visão desses autores desloca-se da concepção que atribui excessivo valor às vivências precoces, que ancorou a ingênua ideia de que o desenvolvimento normal segue um encadeamento linear de constantes avanços, com direção certa e um alvo preciso.

A criança adotiva pode ter em seu histórico de vida um ou mais episódios de abandono e/ou separação. Pode ainda passar por vivências estressantes, ter ou não sofrido violência. Isso é incontestável. O que parece discutível é o fato de esses acontecimentos serem agentes causadores de uma série infindável de catástrofes em seu desenvolvimento, dentre eles a "dificuldade para aprender".

Como argumentou Rutter (1989, p.24) "o ponto não é que continuidades não aconteçam, mas que concepções simplistas de efeitos imutáveis 
precisam ser deixadas de lado em favor de concepções dinâmicas”. Trata-se de abandonar a posição determinista que referenda muitas pesquisas centradas no desenvolvimento do indivíduo adotado, que acabam por apontar um amplo panorama de patologias que, na realidade não são exclusivas das crianças com histórico de privação materna e/ou de institucionalização: podem se instalar tanto em crianças adotivas como naquelas inseridas desde o nascimento na família biológica. É preciso realizar investigações com base em um sistema de inter-relações estabelecidas nos vários contextos de vida desse sujeito, de conceber o desenvolvimento não como um produto, mas como um processo inserido em um contexto internacional amplo.

Apontar as patologias que os adotados desenvolvem ao longo de seu ciclo vital é apenas um dos olhares possíveis sobre a adoção, olhar que apaga outras análises e que se tornou hegemônico devido às condições socioistóricas que o constituíram e o legitimaram. Da mesma forma os estudos que referem psicopatologias como algo comum entre indivíduos adotados generalizam, negando singularidades, tornando tais acontecimentos crônicos, ideias que se repetem no imaginário social. A situação que envolve indivíduos adotivos é muito mais complexa, é multideterminada e contextual, por isso necessita de análises que ultrapassem a fronteira do individual, especialmente quando se trata das "dificuldades de aprendizagem" desses sujeitos, temática ainda pouco investigada e marcada pela incompletude.

Enfim, uma compreensão mais ampla de todo o processo de construção das "dificuldades de aprendizagem" em crianças adotivas, deve vislumbrar e entender melhor a dinâmica de construção deste "sintoma". Deve ampliar o foco de atenção para os diversos componentes presentes nas relações estabelecidas entre a criança e sua aprendizagem. Deslocando o foco de atenção na criança para o conjunto de interações estabelecidas, para o processo de constituição das dificuldades de aprendizagem, é possível entender que estas são construídas nas e por essas interações, de acordo com as posições em que a criança "é colocada" e "se coloca". Nesse sentido, o fato de ter sido dada à adoção passa a ser só uma situação em meio às muitas outras vividas, e perde esse caráter de ser de fundamental importância para a construção das "dificuldades de aprendizagem". E isso muda o sentido, retroage e permite a reconstrução de muitas histórias de aprendizes adotivos. 


\section{REFERÊNCIAS BIBLIOGRÁFICAS}

BADINTER, E. Um amor conquistado: o mito do amor materno. Rio de Janeiro: Nova Fronteira, 1985.

BALONE, G. Crianças adotadas e de orfanato. Disponível em: www.psiqweb.med. br/infantil/ adoc.html. Acesso em: 23 jan. 2003.

BERTHOUD, C. M. E. Filhos do coração. Taubaté: Cabral, 1997.

BRASIL. Estatuto da criança e do adolescente. Brasilia: Ministério da Saúde, Projeto Minha Gente, 1991.

BRINICH, P. M. Some potential effects of adoption on self and object representations. The Psychoanalytics Study of the Child, n.35, p. I07-133, 1980.

CASELATTO, G. Motivos relacionados ao luto que levam um casal à adoção: uma possibilidade psicoprofilática. São Paulo, 1998. Dissert. (mestr.) Pontifícia Universidade Católica de São Paulo, 2000.

CHISHOLM, K. A three year follow-up of attachment and indiscriminate friedliness in children adopted from Romanian orphanages. Child Development, v.69, n.4, p. I .092-1 . I06, Aug. 1998.

COSTA, G. A Família, a criança e o processo de adoção. Revista Psiquiátrica, Porto Alegre, v. 6, n. I, p.30-33, 1984.

CUNHA, J. A.; NUNES, M. L. T. Teste das fábulas: forma verbal e pictórica. Porto Alegre: Centro Editor de Testes e Pesquisas em Psicologia, 1993.

DOLTO, F. Dialogando sobre crianças e adolescentes. Campinas: Papirus, 1989.

DOLTO, F.; HAMAD, N. Destinos de crianças: adoção, família e trabalho social. São Paulo: Martins Fontes, 1998.

FERNANDEZ, A. A Inteligência aprisionada: abordagem psicopedagógica clínica da criança e sua família. Porto Alegre: Artes Médicas, 1990.

FOGEL, A. Developing through relationship: origins of communication, self, and culture. Salt Lake City: University Of Chicago, 1993.

FONSECA, C. Caminhos de adoção. São Paulo: Cortez, 2002.

GARMA, E. G. et al. Acerca de la identificación y la adopción. Revista de Psicoanalisis del Argentina, v.5, n. 42, p. I.057-1.064, 1985.

GUIRADO, M. Instituição e relações afetivas: o vínculo com o abandono. São Paulo: Summus, 1986. 
LEWIS, M. Alterando o destino: por que o passado não prediz o futuro. São Paulo: Moderna, 1999. LEVINZON, G. K. A Criança adotiva na psicoterapia psicanalítica. São Paulo: Escuta, 1999.

LUTHAR, S. S.; ZIGLER, E. Vulnerability and competence: a review of research on resilience in childhood. American Journal of Orthopsychiatry, n. 61, p.6-22, 1991.

MARIANO, F. N. O Cenário jurídico: a análise dos processos de adoção no município de Ribeirão Preto. Ribeirão Preto, 2003. Dissert. (mestr.) Faculdade de Filosofia, Ciências e Letras, Universidade de São Paulo.

MEIRELES, C. Cânticos. 3. ed. São Paulo: Moderna, 1983.

MOTTA, M. A. P. As Marcas do abandono em crianças e adolescentes. Boletim Cecif, n.9. Disponível em: www.cecif.br. Acesso em: 2 mar. 2003.

OLIVEIRA, R. C. S. Crianças e adolescentes (des)acolhidos: a perda da filiação no processo de institucionalização. São Paulo, 200 I. Dissert. (mestr.) Pontifícia Universidade Católica.

PAULI, S. C. de O Sujeito e o sentido em deriva e apagamento da alteridade. Ribeirão Preto, 2002. Tese (dout.) Faculdade de Filosofia, Ciências e Letras, Universidade de São Paulo.

PEREIRA, J. M. F.; SANTOS, M. A. O Enfoque psicológico da adoção: revisão da literatura. In: LABATE, R. C. (org.) Caminhando para a assistência integral. Ribeirão Preto: Scala, 1999. p.225-247.

PICCINI, A. M. A Criança que "não sabia" que era adotiva. Psicologia: Teoria e Pesquisa, Brasília, v. 2, n.2, p.||6-|3|, 1986.

ROSSETTI-FERREIRA, M.C.; AMORIM, K. S.; SILVA, A. P. Rede de significações: alguns conceitos básicos. In: ROSSETTI-FERREIRA, M. C. et al. (orgs.) Rede de significações e o estudo do desenvolvimento humano. São Paulo: Artmed, 2004. p.23-34.

RUTTER, M. L; KREPPNER, J. M.; O'CONNOR, T. G. English and Romanian Adoptees (ERA) study team: specificity and heterogeneity in children's responses to profound institutional privation. The British Journal of Psychiatry, v.97, n. 179, p.97-103, Aug. 2001.

RUTTER, M. Pathways from childhood to adult life. Journal of Child Psychology and Psychiatry, v.30, n. I, p.23-5I, feb. 1989.

. Psychosocial resilience and protective mechanisms. American Journal of Orthopsychiatry, n.57, p.316-331, 1987.

RUTTER, M.; THOMAS, G. Are there biological programming effects for psychological development? Finding from a study of Romanian adoptees. American Psychological Association, v.40, p.8I-94, jan.2004. 
SANTOS, N. P. F. Sentir-se filho e ser filho. In: FREIRE, F. (org.) Abandono e adoção: contribuições para uma cultura da adoção. Curitiba: Terre des Hommes, | 99| . p. I27-I29.

SCHAFFER, H. R. The Early experience assumption: past, present and future. International Journal of Behavioral Development, v.24, n. I, p.5-14, mar.2000.

SPITZ, R. Hospitalism: an inquerity into the genesis of psychiatric conditions in early childhood. Psychoanalitic Study of the Child, n. I, p.53-74, 1945.

WEBER, L. N. D. Pais e filhos por adoção no Brasil. Curitiba: Juruá, 2003.

WIEDER, H. On being told adoption. Psychoanalytic Quartely, n.46, p. I-22, 1977.

WOILER, E. A Condição afetivo-emocional da criança adotada: concessões na aprendizagem, em especial na aprendizagem escolar. São Paulo, 1987. Dissert. (mestr.) Pontifícia Universidade Católica de São Paulo.

ZAVASCHI, M. L. S.; ARAÚJO, M. S. Ansiedades pré-edípicas num menino adotado. Revista Brasileira de Psicanálise, v.22, n.4, p.61 I-620, 1988.

Recebido em: março 2008

Aprovado para publicação em: maio 2008 